REVISTA DE DERECHO UNED, NÚM. 9, 2011

\title{
PROBLEMAS SOCIO-JURÍDICOS EN TORNO A LA CREACIÓN DE UN ESPACIO COMÚN DE EDUCACIÓN SUPERIOR EN LATINOAMÉRICA Y EL CARIBE
}

\author{
Lucía Puertas Bravo \\ Docente-investigadora de la Universidad Técnica Particular de Loja, \\ Ecuador
}

Resumen: En el presente artículo, se exponen los «problemas o amenazas» para la creación de un Espacio Común de Educación Superior en Latinoamérica y el Caribe, que proviene de la experiencia de la Unión Europea, la Convención de Bolonia y de iniciativas de creación de espacios comunes propuestos por algunas organizaciones en América Latina.

Los problemas jurídicos que se analizan parten del hecho de que en nuestro Continente no existe una organización con la misma capacidad de unificación legal de la Unión Europea. Por tanto, la incorporación de un espacio común de educación superior en América Latina y el Caribe, a través de la suscripción de un convenio entre estados, requiere conocer la normativa interna y el proceso para el reconocimiento de las normas internacionales en las constituciones de cada país (primer problema legal). Por otra parte se identifica que no existe libertad de circulación y/o movilidad en nuestra Región, debido a políticas y leyes migratorias (segundo problema legal). Finalmente se considera la situación social de nuestros países como una tercera limitación, dada la heterogeneidad de los sistemas de educación superior y la escasa calidad de la enseñanza y sus instituciones en algunos casos.

Palabras clave: Espacio común, Latinoamérica y el Caribe, edu- 
cación superior, problemas legales, problemas sociales, derecho interno, derecho internacional.

Abstract: This article describes the "problems or threats» for the creation of a Common Space for Higher Education in Latin America and the Caribbean, which comes from the experience of the European Union, the Convention of Bologna, and building initiatives common spaces proposed by some organizations in Latin America.

The legal issues are discussed based on the fact that in our continent there is no organization with the same capacity of legal unification of the European Union. Therefore, the incorporation of a common area of higher education in Latin America and the Caribbean, through the signing of an agreement between states, requires knowledge of the internal rules and the process for international recognition in the constitutions of each country (the first legal problem). On the other hand is identified that there is no freedom of movement and / or mobility in our region, due to migration laws and policies (second legal problem). Finally we consider the social situation of our countries as a third limitation, given the heterogeneity of the systems of higher education and the poor quality of education and its institutions in some cases.

Key words: Common area, Latin America and the Caribbean, higher education, legal issues, social issues, law, international law.

Sumario: I. Introducción.-II. Problemas jurídicos en torno a la integración de un espacio común de educación superior en Latinoamérica y el Caribe.-II.1. Supremacía de la normativa interna sobre la internacional y el proceso para su incorporación en cada país.-II.2. Políticas y leyes migratorias.-III. Diferencias de calidad en la educación superior en América Latina y el Caribe.-III.1. Diferencias en los sistemas educativos.-III.2. Diferencias en la calidad de la enseñanza en los diferentes países de la Región.

\section{INTRODUCCIÓN}

La creación de un espacio Latinoamericano y del Caribe de educación superior nace, sin duda, de la experiencia iniciada por Europa desde 1998 con la Declaración de Sorbona y luego con la Declaración de Bolonia en 1999, en donde se reflexionó sobre la necesidad de la convergencia de un sistema educativo universitario, la estructuración de las titulaciones y la creación del sistema de créditos ECTS 
como un sistema útil para favorecer la movilidad académica por todos los países europeos. Se trata de instaurar un sistema académico basado en torno al alumno y en potencializar su trabajo autónomo. Y, si bien muchos son los críticos de la instauración de este espacio, al que consideran inclusive como causante de mercantilizar la enseñanza y ser más bien una reconversión empresarial en las Universidades públicas, otros muestran las ventajas en torno a este sistema que, sin duda, desde las bases en las que se fundamentan dichas declaraciones, nos llevarían a un sistema que favorece la movilidad estudiantil y consolida las IES y cooperación de la Unión Europea ${ }^{1}$.

Pero ¿por qué crear un espacio común de educación superior en Latinoamérica y el Caribe? Y es que muchos son los «intentos e iniciativas» por consolidar un sistema basado en el modelo europeo adaptado a las condiciones Latinoamericanas que serían consideradas como las ventajas para la creación de este espacio. Sin embargo, por ahora, nos detendremos a exponer los problemas o inconvenientes que en base a una serie de lecturas y planteamientos he identificado, quedando por tanto pendiente para un posterior artículo el análisis de las iniciativas y proyectos que se han formulado en nuestra Región ${ }^{2}$.

Entre otros aspectos que se han considerado, lo más importante es la internacionalización de la Universidad, es decir la cooperación

\footnotetext{
${ }^{1}$ Sobre este tema se puede ampliar en un sinnúmero de bibliografía, entre los que citamos los más trascendentes: GonzÁlez VÁzouEz Antonio, Liebana CHECA José (Coords.) Posibilidades, experiencias y retos en el espacio Europeo de Educación Superior, Granada, Editorial de la Universidad de Granada, 2008; GARcía SuÁREz José Antonio, ¿Qué es el Espacio Europeo de Educación Superior?, el reto de Bolonia. Preguntas y Respuestas, Barcelona, España, Universitat de Barcelona, 2006; Fernández LiRIa Carlos, Serrano García Clara, El Plan Bolonia, Madrid, 2009.

2 Podemos nombrar algunas organizaciones regionales como Parlamento Latinoamericano PARLATINO, Parlamento Andino PARLANDINO, MERCOSUR, UNASUR y otras como las Conferencias Mundiales sobre la Educación Superior en América Latina y el Caribe (1998) y en temas de calidad como IESALC-UNESCO, el Consejo Centroamericano de acreditación de la Educación Superior (CCA); el Instituto Latinoamericano y del Caribe de calidad en educación superior a distancia CALED; y proyectos concretos como: Sistema de Acreditación Regional de Carreras Universitarias de los Estados Partes del Mercosur y Estados Asociados «Sistema ARCU-SUR»; Sistema de evaluación, acreditación y certificación de la educación superior en América Latina y el Caribe, UDUAL; Espacio de Encuentro Latinoamericano y Caribeño de Educación Superior (ENLACES); Proyecto Alfa Tuning América Latina; El Espacio Común de Educación Superior en México (Ecoes); El Sistema de Asignación y Transferencia de Créditos Académicos SATCA; El proyecto de convergencia 6x4, elaborado por ASCUN de Colombia y CENEVAL de México; El Espacio Común de Educación Superior de América Latina, el Caribe y la Unión Europea. (ALCUE); el Espacio Latinoamericano y del Caribe de Educación Superior ELES, propuesto por el Programa CAMPUS de la OUI, entre otros.
} 
regional e interregional la que debe realizarse como un proceso dual (al interior de las universidades y hacia afuera) y que conlleva a que la docencia, investigación y extensión estén presentes en las Instituciones de Educación Superior, manteniéndose estándares comunes de calidad. Y esta calidad involucra la utilización de medios tecnológicos, la acreditación internacional de sus carreras, la movilidad de profesores y estudiantes, participar en proyectos y redes internacionales y su difusión cultural, etc. ${ }^{3}$

Partimos por tanto de algunos hechos que consideramos constituirían los inconvenientes para la creación de un espacio común en nuestra región y es que, a diferencia de los países europeos en donde existe una organización que asocia y vincula jurídicamente a los países que pertenecen a la Unión Europea, en donde las resoluciones que emiten se tornan obligatorias a través de directivas para estos países, en nuestra región existen nueve organizaciones regionales ${ }^{4}$ que podríamos llamarlas más de cooperación y de relaciones internacionales que de integración.

${ }^{3} \mathrm{Al}$ respecto podemos ampliar estos temas en numerosos artículos y textos escritos por importantes autores reconocidos en Latinoamérica como: ARocenA R., Sutz J., La universidad Latinoamericana del futuro, México, Unión de Universidades de América Latina, 2000; BRUNNER, J. J., «Globalización y el futuro de la educación: tendencias, desafíos, estrategias», en OREALC-UNESCO: Seminario sobre Prospectivas de la Educación en América Latina y el Caribe, Santiago de Chile, OREALC 23-25 de agosto de 2000; BrunNer, J. J., Universidad y sociedad en América Latina, Veracruz, Universidad Veracruzana, Instituto de Investigaciones en Educación, 2007; BRUNNER, J. J., Educación Superior en América Latina: cambios y desafíos, Santiago de Chile, Fondo de Cultura Económica, Impresos Lahosa S. A., Primera edición, 1990; GARcía GuAdILLA, C., Tensiones y transiciones, educación superior latinoamericana en los albores del tercer milenio, Caracas Venezuela, Editorial Nueva Sociedad, primera edición, 2002; García Guadilla, C., Conocimiento Educación Superior y Sociedad, Caracas Venezuela, Editorial Nueva Sociedad, primera edición, 1996; García Guadilla, C., Pensadores y forjadores de la universidad latinoamericana, Caracas Venezuela, IESALCUNESCO / CENDES/ bid \& co.editor, 2008; López SEgrera F., (Coord.) América Latina y el Caribe en el siglo XXI, perspectiva y prospectiva de la globalización, México DF, Miguel Angel Porrua, Grupo editorial, 2004; Tünnermann BerheIm C., La Universidad ante los retos del siglo XXI, Mérida, Yucatán, ediciones de la Universidad autónoma de Yucatán, 2003; Declaración mundial sobre educación superior en el siglo XXI, visión y acción, UNESCO, reunión Paris 5 al 9 de octubre de 1998; METAS EDUCATIVAS 2021 La educación que queremos para la generación de los Bicentenarios, Organización de Estados Iberoamericanos para la Educación, la Ciencia y la Cultura, Madrid septiembre de 2008.

${ }^{4}$ Sistema de Integración Centroamericana (SICA), Comunidad Andina (CAN), Asociación Latinoamericana de Integración (ALADI), Mercado Común del Sur (MERCOSUR), Asociación de Estados del Caribe (AEC), Unión de Naciones Suramericanas (UNASUR), Parlamento Latinoamericano (PARLATINO), Parlamento Centroamericano (PARLACEN) y Parlamento Andino (PARLANDINO). 


\section{PROBLEMAS JURÍDICOS EN TORNO A LA INTEGRACIÓN DE UN ESPACIO COMÚN DE EDUCACIÓN SUPERIOR EN LATINOAMÉRICA Y EL CARIBE}

En este apartado señalaremos los problemas jurídicos que hemos podido identificar como posibles amenazas para la instauración de un espacio común de educación superior en Latinoamérica y el Caribe. Partimos de señalar que en nuestra Región encontramos solamente una organización que acoge a los países de Sudamérica, Centro América y el Caribe (PARLATINO) y a su vez ésta conjuntamente con el PARLANDINO, que es parte de la Comunidad Andina, buscan la aproximación y la armonización legislativa para la construcción de espacios comunes, a través de la I Conferencia Interparlamentaria ${ }^{5}$ y la recomendación $\mathrm{N}^{\circ} 200^{6}$ respectivamente. Por otro lado, de las nueve organizaciones regionales existentes, solamente el MERCOSUR y la UNASUR, tienen decisiones, resoluciones y directivas que son obligatorias para los estados partes, y en la última, se tornan obligatorios una vez que hayan sido incorporados en su ordenamiento jurídico.

De todas maneras, la mayoría de estas organizaciones, si bien buscan la cooperación y la integración regional, siguen siendo en su esencia "organizaciones de relaciones internacionales», en donde la incorporación y suscripción de tratados internacionales en la normativa interna de cada país obedece a la voluntad política, su soberanía y a lo dispuesto en sus propias constituciones, en donde podemos encontrar sistemas monistas o dualistas de derecho internacional y supremacía de las normas internas sobre las internacionales o viceversa. Este sería por tanto el primer problema legal

${ }^{5}$ La I Conferencia Interparlamentaria de educación, realizada por la comisión de educación del Parlamento Latinoamericano, se llevó a cabo el 5 y 6 de noviembre de 2006, en la cual entre sus recomendaciones se propone dar inicio al proceso de armonización legislativa en materia educativa en América Latina y el Caribe, e impulsar otras estrategias para la cooperación internacional en esta área y para la integración subregional y regional.

${ }^{6}$ La recomendación $\mathrm{N}^{\circ}$ 200, propuesta por el Parlamento Andino PARLANDINO para la consolidación del Espacio Común Andino para la Educación Superior, la ciencia, la tecnología y la innovación, de fecha 27 de noviembre de 2007, se recomienda, que: los gobiernos de los Países Miembros adelanten acciones definitivas que permitan ejecutar la certificación y competencias y homologación de títulos en la Región Andina y que la comisión segunda del PARLANDINO, establezca canales de cooperación con algunas redes e institutos de la Región acordes al tema, con la finalidad de avanzar en las propuestas y acciones que tengan por objeto la consolidación del Espacio Común Andino, la Tecnología y la Innovación. 
identificado: La supremacía de la normativa interna sobre la internacional y el proceso para su incorporación en cada país.

El segundo problema legal identificado es la no existencia de libertad de circulación de los habitantes de Latinoamérica y del Caribe dentro de la Región, debido a políticas y leyes migratorias que señalan requisitos especiales de permanencia en los países, debiendo sujetarse en algunos casos a la otorgación de visas y documentos migratorios.

\section{II.1 Supremacía de la normativa interna sobre la internacional y el proceso para su incorporación en cada país}

La aplicación del derecho internacional dentro del derecho interno depende de cada estado en particular y sus sistemas constitucionales, ya que muchos de ellos establecen un proceso para la incorporación de un tratado o convenio en su ordenamiento jurídico, (sobre todo los que se refieren a la protección y garantía de los derechos humanos) además de la jerarquía otorgada a lo interno de cada Estado. Muchos países aplican el principio de reciprocidad, es decir que, los acuerdos internacionales, que generalmente se firman entre dos o varios países, deben ser aplicados por sus pares a fin de incorporarlos en su normativa interna para su posterior aplicación.

Para Sorensen ${ }^{7}$, «la relación entre el derecho internacional y el derecho interno, origina varios problemas, muy diferentes de los de las relaciones entre las diferentes reglas de derecho internacional, principalmente porque el derecho de cada Estado constituye un ordenamiento jurídico completo y más o menos cerrado, con sus propias fuentes: la constitución nacional, las leyes, los decretos, la costumbre, y las decisiones judiciales; y sus propios órganos ejecutores: la administración del Estado y los Tribunales.» Es por ello que podría generarse un conflicto a la hora de incorporar un tratado internacional en la normativa interna de los Países de Latinoamérica y el Caribe a través de una organización supranacional para la creación de un espacio común de educación superior.

Con estos antecedentes, a través del siguiente análisis, se busca re-

7 Soensen M., (Edit.) Manual de derecho Internacional Público, México, Fondo de Cultura Económica, 2008, pág. 192. 
alizar un estudio comparado sobre el derecho internacional y el derecho interno. Para ello compararemos las constituciones de los países motivo de nuestra investigación, además de conocer el procedimiento a seguir para la incorporación de un acuerdo o tratado internacional en la legislación interna y si existe supremacía o no de los tratados internacionales:

\begin{tabular}{|c|c|c|}
\hline PAÍS & $\begin{array}{c}\text { RELACIONES ENTRE } \\
\text { EL DERECHO } \\
\text { INTERNACIONAL Y EL DE- } \\
\text { RECHO INTERNO }\end{array}$ & $\begin{array}{l}\text { PROCESO PARA } \\
\text { APROBACIÓN } \\
\text { DE TRATADOS } \\
\text { INTERNACIONALES }\end{array}$ \\
\hline Argentina & $\begin{array}{l}\text { La constitución, las leyes de la } \\
\text { Nación y los tratados con las po- } \\
\text { tencias extranjeras son ley su- } \\
\text { prema de la Nación (Art. } 31 \\
\text { Constitución Nacional). } \\
\text { Los tratados y concordatos tie- } \\
\text { nen jerarquía superior a las le- } \\
\text { yes. }\end{array}$ & $\begin{array}{l}\text { Los tratados y convenciones so- } \\
\text { bre derechos humanos, luego de } \\
\text { ser aprobados por el Congreso, } \\
\text { requerirán el voto de las dos ter- } \\
\text { ceras partes de la totalidad de } \\
\text { los miembros de cada Cámara } \\
\text { para gozar de la jerarquía cons- } \\
\text { titucional. } \\
\text { Para la aprobación de tratados } \\
\text { de integración que deleguen } \\
\text { competencia y jurisdicción a or- } \\
\text { ganizaciones supra- estatales en } \\
\text { condiciones de reciprocidad e } \\
\text { igualdad, y que respeten el orden } \\
\text { democrático y los derechos hu- } \\
\text { manos requieren la mayoría ab- } \\
\text { soluta de la totalidad de los } \\
\text { miembros de cada Cámara. }\end{array}$ \\
\hline Bolivia & $\begin{array}{l}\text { Los tratados y convenios inter- } \\
\text { nacionales ratificados por la } \\
\text { Asamblea Legislativa Plurinacio- } \\
\text { nal, que reconocen los derechos } \\
\text { humanos prevalecen en el orden } \\
\text { interno. } \\
\text { Los tratados internacionales ra- } \\
\text { tificados forman parte del orde- } \\
\text { namiento jurídico interno con } \\
\text { rango de ley. }\end{array}$ & $\begin{array}{l}\text { Los tratados internacionales ra- } \\
\text { tificados requieren aprobación } \\
\text { mediante referendo popular } \\
\text { cuando impliquen: cesión de } \\
\text { competencias institucionales a } \\
\text { organismos internacionales o su- } \\
\text { pranacionales, en el marco de } \\
\text { procesos de integración. } \\
\text { Los procedimientos de celebra- } \\
\text { ción de tratados internacionales } \\
\text { se regularán por la ley. } \\
\text { Se promueve la integración de } \\
\text { los estados sobre todo la Latino- } \\
\text { americana. }\end{array}$ \\
\hline
\end{tabular}




\begin{tabular}{|c|c|c|}
\hline PAÍS & $\begin{array}{c}\text { RELACIONES ENTRE } \\
\text { EL DERECHO } \\
\text { INTERNACIONAL Y EL DE- } \\
\text { RECHO INTERNO }\end{array}$ & $\begin{array}{l}\text { PROCESO PARA } \\
\text { APROBACIÓN } \\
\text { DE TRATADOS } \\
\text { INTERNACIONALES }\end{array}$ \\
\hline \begin{tabular}{|l|} 
Brasil \\
\end{tabular} & $\begin{array}{l}\text { Las relaciones internacionales } \\
\text { tienen algunos principios, en } \\
\text { donde prevalecen los derechos } \\
\text { humanos. } \\
\text { Los derechos y garantías expre- } \\
\text { sadas en la Constitución no ex- } \\
\text { cluyen otros derivados del régi- } \\
\text { men y de los principios por ella } \\
\text { adoptados, o de los tratados in- } \\
\text { ternacionales que Brasil sea par- } \\
\text { te. }\end{array}$ & $\begin{array}{l}\text { Al Presidente de la República le } \\
\text { compete celebrar tratados, con- } \\
\text { venciones y actos internaciona- } \\
\text { les sujetos a referendo del Con- } \\
\text { greso Nacional. } \\
\text { Se estipula en su constitución que } \\
\text { Brasil buscará la integración } \\
\text { económica, política, social y cul- } \\
\text { tural de América Latina, a la for- } \\
\text { mación de una comunidad lati- } \\
\text { noamericana de naciones. }\end{array}$ \\
\hline Chile & $\begin{array}{l}\text { Se otorga rango de ley a los tra- } \\
\text { tados internacionales ya que } \\
\text { para su aprobación, la constitu- } \\
\text { ción establece el mismo trámite } \\
\text { que una ley. } \\
\text { Su incorporación en la normati- } \\
\text { va interna solamente inicia con } \\
\text { su publicación en el Diario Ofi- } \\
\text { cial. }\end{array}$ & $\begin{array}{l}\text { Le corresponde al Presidente de } \\
\text { la República conducir las rela- } \\
\text { ciones políticas extranjeras y or- } \\
\text { ganismos internacionales y lle- } \\
\text { var a cabo las negociaciones; } \\
\text { concluir, firmar y ratificar los } \\
\text { tratados que estime convenien- } \\
\text { tes para los intereses del país los } \\
\text { que deberán ser sometidos a la } \\
\text { aprobación del Congreso. }\end{array}$ \\
\hline Colombia & $\begin{array}{l}\text { Se reconoce los principios del } \\
\text { derecho internacional, prevale- } \\
\text { ciendo en el orden interno los } \\
\text { tratados y convenios internacio- } \\
\text { nales ratificados por el Congre- } \\
\text { so, que reconocen los derechos } \\
\text { humanos. }\end{array}$ & $\begin{array}{l}\text { Se promueve la integración, so- } \\
\text { bre todo la Latinoamericana y } \\
\text { del Caribe. }\end{array}$ \\
\hline Ecuador & $\begin{array}{l}\text { Los tratados internacionales ra- } \\
\text { tificados por el Ecuador se suje- } \\
\text { tarán a lo establecido en la cons- } \\
\text { titución. } \\
\text { En los tratados de derechos hu- } \\
\text { manos se aplicará los principios } \\
\text { pro ser humano. }\end{array}$ & $\begin{array}{l}\text { La facultad para la suscripción } \\
\text { de tratados e instrumentos inter- } \\
\text { nacionales, la tiene el Presidente } \\
\text { de la República, el que deberá } \\
\text { informar a la Asamblea Nacio- } \\
\text { nal de todos los tratados que } \\
\text { suscriba. Para casos especiales: } \\
\text { "contengan el compromiso de } \\
\text { expedir, modificar o derogar una } \\
\text { ley», «se refieran a los derechos } \\
\text { y garantías establecidas en la } \\
\text { Constitución», "Atribuyan com- } \\
\text { petencias propias del orden jurí- } \\
\text { dico interno a un organismo in- } \\
\text { ternacional o supranacional», se } \\
\text { requiere la aprobación previa } \\
\text { por la Asamblea. } \\
\text { Se promueve la integración Lati- } \\
\text { noamericana. }\end{array}$ \\
\hline
\end{tabular}




\begin{tabular}{|c|c|c|}
\hline PAÍS & $\begin{array}{c}\text { RELACIONES ENTRE } \\
\text { EL DERECHO } \\
\text { INTERNACIONAL Y EL DE- } \\
\text { RECHO INTERNO }\end{array}$ & $\begin{array}{l}\text { PROCESO PARA } \\
\text { APROBACIÓN } \\
\text { DE TRATADOS } \\
\text { INTERNACIONALES }\end{array}$ \\
\hline Paraguay & $\begin{array}{l}\text { Los tratados internacionales vá- } \\
\text { lidamente celebrados, forman } \\
\text { parte del ordenamiento legal in- } \\
\text { terno. } \\
\text { La Constitución tiene jerarquía } \\
\text { sobre los Convenios y Tratados } \\
\text { Internacionales aprobados y ra- } \\
\text { tificados. }\end{array}$ & $\begin{array}{l}\text { Se aprueban por ley del Congre- } \\
\text { so. } \\
\text { Se admite un orden jurídico su- } \\
\text { pranacional que garantice la vi- } \\
\text { gencia de los derechos humanos, } \\
\text { de la paz, de la justicia, de la co- } \\
\text { operación y del desarrollo, en lo } \\
\text { político, económico, social y cul- } \\
\text { tural. } \\
\text { Dichas decisiones sólo podrán } \\
\text { adoptarse por mayoría absoluta } \\
\text { de cada Cámara del Congreso. }\end{array}$ \\
\hline Perú & $\begin{array}{l}\text { La Constitución prevalece sobre } \\
\text { toda norma legal. } \\
\text { Los tratados celebrados por el } \\
\text { Estado y en vigor forman parte } \\
\text { del derecho nacional. } \\
\text { Cuando el tratado afecte dispo- } \\
\text { siciones constitucionales debe } \\
\text { ser aprobado por el mismo pro- } \\
\text { cedimiento que rige la reforma } \\
\text { de la Constitución, antes de ser } \\
\text { ratificado por el Presidente de la } \\
\text { República. }\end{array}$ & $\begin{array}{l}\text { Los tratados deben ser aproba- } \\
\text { dos por el Congreso antes de su } \\
\text { ratificación por el Presidente de } \\
\text { la República, cuando versen en- } \\
\text { tre otros sobre derechos huma- } \\
\text { nos o cuando modifiquen o de- } \\
\text { roguen alguna ley. } \\
\text { La constitución Peruana pro- } \\
\text { mueve la integración, particular- } \\
\text { mente latinoamericana. }\end{array}$ \\
\hline Uruguay & $\begin{array}{l}\text { No se establece / la doctrina y la } \\
\text { jurisprudencia equiparan los tra- } \\
\text { tados internacionales a la jerar- } \\
\text { quía de ley. }\end{array}$ & $\begin{array}{l}\text { En los tratados internacionales } \\
\text { que celebre la República pro- } \\
\text { pondrá la cláusula de que todas } \\
\text { las diferencias que surjan entre } \\
\text { las partes contratantes, serán de- } \\
\text { cididas por el arbitraje u otros } \\
\text { medios pacíficos. La República } \\
\text { procurará la integración social y } \\
\text { económica de los Estados Lati- } \\
\text { noamericanos. }\end{array}$ \\
\hline Venezuela & $\begin{array}{l}\text { Los tratados, pactos y conven- } \\
\text { ciones relativos a derechos hu- } \\
\text { manos, suscritos y ratificados } \\
\text { por Venezuela, tienen jerarquía } \\
\text { constitucional y prevalecen en el } \\
\text { orden interno, en la medida en } \\
\text { que contengan normas sobre su } \\
\text { goce y ejercicio más favorables } \\
\text { a las establecidas por la Consti- } \\
\text { tución y la ley de la República, y } \\
\text { son de aplicación inmediata y di- } \\
\text { recta por los tribunales y demás } \\
\text { órganos del Poder Público. }\end{array}$ & $\begin{array}{l}\text { Los tratados deben ser aproba- } \\
\text { dos por la Asamblea Nacional } \\
\text { antes de su ratificación por el } \\
\text { Presidente de la República. } \\
\text { Se promueve la integración Lati- } \\
\text { noamericana y Caribeña, "Las } \\
\text { normas que se adopten en el } \\
\text { marco de los acuerdos de inte- } \\
\text { gración serán consideradas parte } \\
\text { integrante del ordenamiento le- } \\
\text { gal vigente y de aplicación direc- } \\
\text { ta y preferente a la legislación } \\
\text { interna. }\end{array}$ \\
\hline
\end{tabular}




\begin{tabular}{|c|c|c|}
\hline PAÍS & $\begin{array}{c}\text { RELACIONES ENTRE } \\
\text { EL DERECHO } \\
\text { INTERNACIONAL Y EL DE- } \\
\text { RECHO INTERNO }\end{array}$ & $\begin{array}{l}\text { PROCESO PARA } \\
\text { APROBACIÓN } \\
\text { DE TRATADOS } \\
\text { INTERNACIONALES }\end{array}$ \\
\hline Costa Rica & $\begin{array}{l}\text { Los tratados públicos, los conve- } \\
\text { nios internacionales y los con- } \\
\text { cordatos tienen desde su pro- } \\
\text { mulgación autoridad superior a } \\
\text { las leyes. }\end{array}$ & $\begin{array}{l}\text { Los tratados y convenios inter- } \\
\text { nacionales deben ser aprobados } \\
\text { por la Asamblea Legislativa y } \\
\text { cuando atribuyan o transfieran } \\
\text { determinadas competencias a un } \\
\text { ordenamiento jurídico comuni- } \\
\text { tario con el propósito de reali- } \\
\text { zar objetivos regionales y comu- } \\
\text { nes requieren una votación no } \\
\text { menor a los dos tercios de la to- } \\
\text { talidad de sus miembros. }\end{array}$ \\
\hline El Salvador & $\begin{array}{l}\text { Los tratados internacionales } \\
\text { constituyen leyes de la Repúbli- } \\
\text { ca cuando entran en vigencia. } \\
\text { Tienen supremacía sobre las le- } \\
\text { yes pero no sobre la Constitu- } \\
\text { ción. }\end{array}$ & $\begin{array}{l}\text { A la Asamblea Legislativa le } \\
\text { compete ratificar los tratados o } \\
\text { pactos que celebre el ejecutivo } \\
\text { con otros estados u organismos } \\
\text { internacionales o denegar su ra- } \\
\text { tificación. } \\
\text { Se promueve la integración hu- } \\
\text { mana, económica social y cultu- } \\
\text { ral con las repúblicas america- } \\
\text { nas especialmente con las Cen- } \\
\text { troamericanas. Para ello puede } \\
\text { efectuarse mediante tratados o } \\
\text { convenios que podrá contemplar } \\
\text { la creación de un organismo con } \\
\text { funciones supranacionales. }\end{array}$ \\
\hline Guatemala & $\begin{array}{l}\text { En materia de derechos huma- } \\
\text { nos, los tratados y convenciones } \\
\text { aceptados y ratificados por Gua- } \\
\text { temala, tienen preeminencia so- } \\
\text { bre el derecho interno. } \\
\text { Existe jerarquía constitucional } \\
\text { (Art. 175), ninguna ley puede } \\
\text { contrariar lo señalado en la Cons- } \\
\text { titución. } \\
\end{array}$ & $\begin{array}{l}\text { Le compete al Congreso, apro- } \\
\text { bar antes de su ratificación los } \\
\text { tratados y convenios internacio- } \\
\text { nales entre otros cuando afecten } \\
\text { las leyes vigentes. }\end{array}$ \\
\hline Honduras & $\begin{array}{l}\text { Los tratados internacionales ce- } \\
\text { lebrados por Honduras con } \\
\text { otros estados, una vez que en- } \\
\text { tran en vigor, forman parte del } \\
\text { derecho interno. } \\
\text { Tienen supremacía sobre la Ley, } \\
\text { y cuando afecte una disposición } \\
\text { constitucional debe ser aproba- } \\
\text { do por el mismo procedimiento } \\
\text { para una reforma a la constitu- } \\
\text { ción antes de ser ratificado por } \\
\text { el Ejecutivo. }\end{array}$ & $\begin{array}{l}\text { Todos los tratados internaciona- } \\
\text { les deben ser aprobados por el } \\
\text { Congreso Nacional antes de su } \\
\text { ratificación por el Poder Ejecuti- } \\
\text { vo. }\end{array}$ \\
\hline
\end{tabular}




\begin{tabular}{|c|c|c|}
\hline PAÍS & $\begin{array}{c}\text { RELACIONES ENTRE } \\
\text { EL DERECHO } \\
\text { INTERNACIONAL Y EL DE- } \\
\text { RECHO INTERNO }\end{array}$ & $\begin{array}{l}\text { PROCESO PARA } \\
\text { APROBACIÓN } \\
\text { DE TRATADOS } \\
\text { INTERNACIONALES }\end{array}$ \\
\hline Nicaragua & No se establece. & $\begin{array}{l}\text { Corresponde a la Asamblea Le- } \\
\text { gislativa, aprobar, modificar o } \\
\text { improbar los tratados celebrados } \\
\text { con naciones extranjeras. } \\
\text { Es atribución del Presidente de } \\
\text { la República, ratificar definitiva- } \\
\text { mente los tratados cuyo objeto } \\
\text { sea la unión de Nicaragua con } \\
\text { uno o más Estados de Centro } \\
\text { América. }\end{array}$ \\
\hline Panamá & $\begin{array}{l}\text { La República de Panamá acata } \\
\text { las normas del Derecho Interna- } \\
\text { cional. }\end{array}$ & $\begin{array}{l}\text { A la Asamblea Legislativa le } \\
\text { compete aprobar o desaprobar } \\
\text { antes de su ratificación por el } \\
\text { Ejecutivo, los tratados y conve- } \\
\text { nios internacionales. }\end{array}$ \\
\hline México & $\begin{array}{l}\text { La Constitución, las leyes y to- } \\
\text { dos los Tratados que estén de } \\
\text { acuerdo con la misma, serán la } \\
\text { Ley Suprema de toda la Unión. } \\
\text { Las normas relativas a los dere- } \\
\text { chos humanos se interpretarán } \\
\text { de conformidad con esta Consti- } \\
\text { tución y con los tratados inter- } \\
\text { nacionales de la materia. }\end{array}$ & $\begin{array}{l}\text { Es facultad del Senado, aprobar } \\
\text { los tratados internacionales y } \\
\text { convenciones diplomáticas que } \\
\text { el Ejecutivo Federal suscriba, así } \\
\text { como su decisión de terminar, } \\
\text { denunciar, suspender, modificar, } \\
\text { enmendar, retirar reservas y for- } \\
\text { mular declaraciones interpreta- } \\
\text { tivas sobre los mismos. }\end{array}$ \\
\hline Cuba & $\begin{array}{l}\text { Funda sus relaciones internacio- } \\
\text { nales en los principios de igual- } \\
\text { dad de derechos, libre determi- } \\
\text { nación de los pueblos, integridad } \\
\text { territorial, independencia de los } \\
\text { Estados, la cooperación interna- } \\
\text { cional en beneficio e interés mu- } \\
\text { tuo y equitativo, el arreglo pací- } \\
\text { fico de controversias en pie de } \\
\text { igualdad y respeto y los demás } \\
\text { principios proclamados en la } \\
\text { Carta de las Naciones Unidas y } \\
\text { en otros tratados internaciona- } \\
\text { les de los cuales Cuba sea parte. }\end{array}$ & $\begin{array}{l}\text { Son atribuciones del Consejo de } \\
\text { Ministros Estado, aprobar trata- } \\
\text { dos internacionales y someterlos } \\
\text { a la ratificación del Consejo de } \\
\text { Estado. } \\
\text { Se establece su voluntad de inte- } \\
\text { gración y colaboración con los } \\
\text { países de América Latina y del } \\
\text { Caribe. }\end{array}$ \\
\hline Haití & $\begin{array}{l}\text { Tiene supremacía la constitu- } \\
\text { ción. } \\
\text { Los tratados o convenios inter- } \\
\text { nacionales aprobados y ratifica- } \\
\text { dos se convierten en parte de la } \\
\text { legislación del país y derogan las } \\
\text { leyes en conflicto con ellos. }\end{array}$ & $\begin{array}{l}\text { Los poderes de la Asamblea son } \\
\text { aprobar o rechazar los convenios } \\
\text { y acuerdos internacionales. }\end{array}$ \\
\hline
\end{tabular}




\begin{tabular}{|l|l|l|}
\hline \multicolumn{1}{|c|}{ PAÍS } & \multicolumn{1}{c|}{$\begin{array}{c}\text { RELACIONES ENTRE } \\
\text { EL DERECHO } \\
\text { INTERNACIONAL Y EL DE- } \\
\text { RECHO INTERNO }\end{array}$} & \multicolumn{1}{c|}{$\begin{array}{c}\text { PROCESO PARA } \\
\text { APROBACIÓN } \\
\text { DE TRATADOS } \\
\text { INTERNACIONALES }\end{array}$} \\
\hline $\begin{array}{l}\text { República } \\
\text { Dominicana }\end{array}$ & $\begin{array}{l}\text { Reconoce y aplica las normas } \\
\text { del Derecho Internacional gene- } \\
\text { ral y americano en la medida en } \\
\text { que sus poderes públicos las ha- } \\
\text { yan adoptado. }\end{array}$ & $\begin{array}{l}\text { Son atribuciones del Congreso, } \\
\text { aprobar o desaprobar los trata- } \\
\text { dos y convenciones internacio- } \\
\text { nales que celebre el Poder Eje- } \\
\text { cutivo. }\end{array}$ \\
\hline
\end{tabular}

Con lo señalado, podemos constituir cuatro maneras diferentes de incorporar y jerarquizar los instrumentos internacionales dentro de las constituciones de los países de Latinoamérica y el Caribe ${ }^{8}$ :

a) Modelo Supranacional: Derecho internacional de los Derechos Humanos que puede modificar la Constitución. A este modelo se adscriben Honduras, Guatemala ${ }^{9}$, Perú ${ }^{10}$ y Venezuela.

b) Modelo Constitucional: Derecho internacional de los Derechos Humanos equiparado a la constitución. Se destacan, Argentina y Brasil ${ }^{11}$.

c) Modelo supralegal: Derecho internacional de los Derechos Humanos por debajo de la constitución pero por encima de las leyes nacionales. Aquí se enmarcan la mayoría de países pertenecientes a Latinoamérica y el Caribe, Costa Rica, Colombia, Ecuador, El Salvador, Haití, Paraguay, República Dominicana.

8 Clasificación realizada por Henderson H., «Los tratados internacionales de derechos humanos en el orden interno: la importancia del principio pro homine», Revista IIDH, Volumen 39, 2004, pp. 71-99.

${ }_{9}^{9}$ Debemos considerar que a pesar de lo establecido en el Art. 46 de la Constitución de Guatemala (Preeminencia del Derecho Internacional) en donde se establece el principio general de que en materia de derechos humanos, los tratados y convenciones aceptados y ratificados por Guatemala, tienen preeminencia sobre el derecho interno, el Art. 175 señala que ninguna ley puede contrariar las disposiciones de la Constitución. (Jerarquía constitucional).

${ }^{10}$ Henderson ubica a Perú en la clasificación de constitucional, e incluso que podría tener la categoría de supraconstitucional. Lo clasifico con jerarquía supraconstitucional debido a que su constitución en el Art. 57 señala que: «Cuando el tratado afecte disposiciones constitucionales debe ser aprobado por el mismo procedimiento que rige la reforma de la Constitución, antes de ser ratificado por el Presidente de la República», es decir es posible reformar la constitución.

11 Brasil podría considerarse en la categoría supraconstitucional ya que su constitución señala que «Los derechos y garantías expresadas en esta Constitución no excluyen otros derivados del régimen y de los principios por ella adoptados, o de los tratados internacionales en que la República Federativa de Brasil sea parte». 
d) Modelo Legal: Derecho internacional de los Derechos Humanos equiparado a las leyes nacionales. Entre los países adscritos a este modelo cabe destacar Bolivia, Chile, Cuba ${ }^{12}$, México ${ }^{13}$, Panamá ${ }^{14}$, Uruguay.

Por otro lado, se considera, dentro de las relaciones entre el derecho internacional y el derecho interno, dos criterios opuestos: la escuela dualista, que sostiene que los dos sistemas son totalmente distintos e incapaces de ninguna penetración mutua, y la escuela monista, que considera a ambos derechos unidos. En teoría el derecho internacional en Latinoamérica y el Caribe se constituye como un sistema monista ya que es incorporado en la normativa interna, con la jerarquía señalada anteriormente.

Dentro de las características comunes que se observan en las constituciones estudiadas, en los países como Bolivia, Brasil, Colombia, Ecuador, Perú, Uruguay, Venezuela, El Salvador y Cuba, se promueve la integración de los países, especialmente la Latinoamericana y del Caribe. Además en algunos de ellos se establece la creación de un organismo supranacional (Bolivia, Colombia y el Salvador), a fin de promover estas relaciones. Podemos destacar también ciertos principios establecidos, como en la Brasilera, que considera entre ellos: la prevalencia de los derechos humanos, la igualdad entre los estados, la cooperación entre los pueblos para el progreso de la humanidad. Bolivia considera: la independencia e igualdad entre los estados; defensa y promoción de los derechos humanos, económicos, sociales, culturales y ambientales; cooperación y solidaridad entre los estados y pueblos. Colombia menciona bases de equidad, igualdad y reciprocidad. Ecuador por su parte, la constitución en su título VIII, establece algunos principios sobre los cuales deben basarse las relaciones internacionales, que deben, «responder a los in-

12 A pesar de no estar expresado en su constitución, su artículo 3 señala que «En la República de Cuba la soberanía reside en el pueblo, del cual dimana todo el poder del Estado. Ese poder es ejercido directamente o por medio de las Asambleas del Poder Popular y demás órganos del Estado que de ellas se derivan, en la forma y según las normas fijadas por la Constitución y las leyes».

${ }^{13}$ Existe un fallo interpretativo de la suprema corte en donde se ubica a los Tratados Internacionales por debajo de la constitución pero por encima de las leyes nacionales, otorgándose por ende el rango de supralegal (HENDERSON H., op. cit., p. 81).

${ }^{14}$ Si bien su constitución establece que «La República de Panamá acata las normas del derecho internacional», no se estipula con que jerarquía, por lo que si consideramos el Art. 231: «las autoridades principales tienen el deber de cumplir y hacer cumplir la Constitución y Leyes de la República, los decretos y órdenes del Ejecutivo y las resoluciones de los Tribunales de la justicia ordinaria y administrativa» ubicaríamos al derecho internacional en la categoría de legal. 
tereses del pueblo ecuatoriano». Algunos de estos principios son: la independencia e igualdad jurídica de los Estados, la convivencia pacífica y la autodeterminación de los pueblos; el principio de ciudadanía universal, la libre movilidad de todos los habitantes; el respeto a los derechos humanos en particular el de las personas migrantes. Paraguay, establece entre sus principios: la independencia nacional, la autodeterminación de los pueblos, la igualdad jurídica entre los estados, la solidaridad y la cooperación internacional, la protección internacional de los derechos humanos. En Venezuela se observa: la independencia, igualdad entre los estados, libre determinación, solución pacífica de conflictos internacionales, cooperación y respeto de los derechos humanos.

Si conceptuamos que todas las constituciones en nuestra región reconocen los derechos humanos (derecho a la educación) y los tratados internacionales dentro de su ordenamiento jurídico (cualquiera que sea su jerarquía), en teoría no sería un impedimento el incorporar un convenio supranacional que cree un espacio común de educación superior, considerando el derecho a la educación de sus habitantes, y, por tanto, se podría invocar el principio pro homine que para Henderson, «se basa en que los derechos inherentes a la persona humana reconocidos por la conciencia jurídica universal, deben ser protegidos frente al accionar ilegítimo del Estado, así como frente a la institucionalidad estatal, a sus agentes, empleados, funcionarios o servidores públicos, las cadenas de mando, los grupos clandestinos, e irregularidades a su servicio, así como la red de relaciones institucionales que favorecen, permiten o amparan las violaciones de derechos en un escenario de impunidad ${ }^{15}$.

De todas maneras si surgiere un conflicto entre el derecho interno y el derecho internacional y la aplicación de un tratado o convenio dentro de un Estado, podemos estipular la prevalencia de un instrumento internacional fundamentado en los derechos humanos (el derecho a la educación) y además lo establecido en la Convención de Viena ${ }^{16}$, en donde se reconoce a los tratados como fuente del derecho internacional y como medio de desarrollar la cooperación pacífica entre las naciones.

15 Henderson H., op. cit., p. 21.

${ }_{16}$ Esta convención se fundamenta en los principios y propósitos de la Carta de las Naciones Unidas, que se refieren a la igualdad de derechos entre los estados, la libre determinación de los pueblos, la cooperación en la solución de problemas internacionales de carácter económico, social, cultural o humanitario y el desarrollo y estímulo del respeto a los derechos humanos. 
Esta convención, al ser aplicada para los tratados, en caso de controversia entre los dos sistemas o del incumplimiento de éste, seguirá prevaleciendo el derecho internacional: «Una parte no podrá invocar las disposiciones de su derecho interno como justificación del incumplimiento de un tratado» (Art. 27); «El hecho de que el consentimiento de un Estado en obligarse por un tratado haya sido manifiesto en violación de una disposición de su derecho interno concerniente a la competencia para celebrar tratados no podrá ser alegado por dicho Estado como vicio de su consentimiento, a menos que esa violación sea manifiesta y afecte a una norma de importancia fundamental de su derecho interno» (Art. 46). Ello considerando además que un Estado forma "parte» ${ }^{17}$ de un tratado o convenio, el cual lo suscribe con "plenos poderes» ${ }^{18}$.

Finalmente es necesario considerar otro factor que pudiera influir negativamente en las relaciones internacionales y por consiguiente en la incorporación de un tratado o convenio en la normativa interna como lo es la inestabilidad política de nuestros países, ya que si bien el derecho internacional está regulado o establecido en sus constituciones, bien podría un gobierno de turno por «conveniencia de estado» reformar la constitución y por ende cambiar sus políticas y relaciones internacionales.

\section{II.2. Políticas y leyes migratorias}

Como recordaremos uno de los fundamentos de la creación de un espacio común de educación superior en Latinoamérica y el Caribe es la movilidad académica, en donde profesores y alumnos tendrían la facultad de realizar estancias a fin de adquirir las competencias necesarias y su libre elección de hacerlo en cualquier país de la región y/o adquirir nuevos conocimientos a través de estudios e investigaciones. Esta movilidad académica podría verse impedida por una barrera migratoria, dada por las leyes y políticas en esta materia

17 «Se entiende por «parte» un Estado que ha consentido en obligarse por el tratado y con respecto al cual el tratado está en vigor. Art. 2 Convención de Viena, literal g).

18 "Se entiende por "plenos poderes" un documento que emana de la autoridad competente de un Estado y por el que se designa a una o varias personas para representar al Estado en la negociación, la adopción o la autenticación del texto de un tratado, para expresar el consentimiento del Estado en obligarse por un tratado, o para ejecutar cualquier otro acto con respecto a un tratado» Art. 2 Convención de Viena, literal c. 
existentes en nuestros países. Es por ello que a continuación se analizarán las leyes de extranjería, migración, inmigración u otras, a fin de establecer preceptos tanto generales con respecto a la movilidad de extranjeros, así como normas específicas para el caso de estudiantes.

En cuanto a los primeros, en los países como: Ecuador, Argentina, Chile, Costa Rica, El Salvador, Guatemala, Honduras, Nicaragua, Panamá, Perú, Uruguay, Venezuela, y República Dominicana, sus normas migratorias ordenan y regulan los flujos migratorios, ingreso, egreso y permanencia de las personas que deseen adquirir alguna de las categorías migratorias, así como sus derechos y obligaciones dentro del territorio nacional, que se encuentren en armonía con los tratados internacionales suscritos. En los países como Bolivia, Colombia y Paraguay, sus leyes migratorias además de lo señalado, buscan favorecer la movilización con fines demográficos, sociales, culturales económicos, científicos, de seguridad, etc., y además que fomenten el desarrollo y progreso de los estados, promuevan la fuerza de trabajo, creen e impulsen proyectos que dinamicen el desarrollo del país en todos sus ámbitos. Es decir buscan el beneficio tanto para los extranjeros, así como para los nacionales, otorgándoles garantías necesarias y protecciones legales, a fin de que puedan realizar actividades que coadyuven el progreso de los estados.

De manera específica, se puede observar que en la mayoría de países dentro de las categorías migratorias existentes, encontramos una específica que enmarca a los estudiantes y profesores y que permite realizar actividades netamente académicas, previo a lo señalado en cada una de ellas:

\begin{tabular}{|l|l|l|l|}
\hline \multicolumn{1}{|c|}{ PAÍS } & \multicolumn{1}{|c|}{ CATEGORÍA } & $\begin{array}{c}\text { ¿SE DEBE } \\
\text { REALIZAR UN } \\
\text { TRÁMITE } \\
\text { ESPECIAL? }\end{array}$ & \multicolumn{1}{c|}{$\begin{array}{c}\text { TIEMPO } \\
\text { MÁXIMO DE } \\
\text { PERMANENCIA }\end{array}$} \\
\hline Argentina & $\begin{array}{l}\text { Residentes tempora- } \\
\text { rios }\end{array}$ & $\begin{array}{l}\text { Si } \\
\text { coños prorrogables, } \\
\text { das múltiples. }\end{array}$ \\
\hline Bolivia & Inmigrantes selecti- & $\begin{array}{l}\text { Se promueve el in- } \\
\text { greso de extranjeros } \\
\text { que favorezcan el de- } \\
\text { sarrollo del país. }\end{array}$ & $\begin{array}{l}\text { 60 días con amplia- } \\
\text { ción hasta un año. }\end{array}$ \\
\hline Chile & Residente estudiante & $\begin{array}{l}\text { Visa / Se autoriza la } \\
\text { permanencia defini- } \\
\text { tiva para ejercicio } \\
\text { profesional de estu- } \\
\text { diantes extranjeros. }\end{array}$ & $\begin{array}{l}\text { 1 año, pudiendo ser } \\
\text { don iguales y sucesi- } \\
\text { vos. }\end{array}$ \\
\hline
\end{tabular}




\begin{tabular}{|c|c|c|c|}
\hline PAÍS & CATEGORÍA & $\begin{array}{c}\text { ¿SE DEBE } \\
\text { REALIZAR UN } \\
\text { TRÁMITE } \\
\text { ESPECIAL? }\end{array}$ & $\begin{array}{c}\text { TIEMPO } \\
\text { MÁXIMO DE } \\
\text { PERMANENCIA }\end{array}$ \\
\hline Colombia & $\begin{array}{l}\text { Temporal de estu- } \\
\text { diante }\end{array}$ & $\begin{array}{l}\text { Visa temporal previo } \\
\text { cumplimiento de re- } \\
\text { quisitos específicos. }\end{array}$ & $\begin{array}{l}1 \text { año, pudiendo ser } \\
\text { renovada por perío- } \\
\text { dos iguales hasta fi- } \\
\text { nalización de los es- } \\
\text { tudios y obtención de } \\
\text { título. }\end{array}$ \\
\hline Costa Rica & $\begin{array}{l}\text { Categoría migratoria } \\
\text { especial de estudian- } \\
\text { te }\end{array}$ & $\begin{array}{l}\text { Si / se considera co- } \\
\text { mo una categoría es- } \\
\text { pecial, prohibiéndose } \\
\text { realizar actividades } \\
\text { remuneradas, además } \\
\text { deben abandonar el } \\
\text { país una vez culmina- } \\
\text { dos sus estudios. }\end{array}$ & $\begin{array}{l}1 \text { año con prórroga } \\
\text { de hasta dos años. }\end{array}$ \\
\hline Ecuador & No inmigrante & Visa & $\begin{array}{l}\text { Se otorga para un } \\
\text { mínimo de seis me- } \\
\text { ses y un máximo de } \\
\text { un año que puede ser } \\
\text { renovado. }\end{array}$ \\
\hline El Salvador & Residente temporal & $\begin{array}{l}\text { Visa temporal hasta } \\
\text { culminación de sus } \\
\text { estudios. }\end{array}$ & 1 año. \\
\hline Guatemala & Residente temporal & $\begin{array}{l}\text { Visa previo cumpli- } \\
\text { miento de requisitos } \\
\text { especiales. }\end{array}$ & No se establece. \\
\hline Honduras & Residentes especiales & $\begin{array}{l}\text { Visa previo cumpli- } \\
\text { miento de requisitos } \\
\text { especiales. }\end{array}$ & $\begin{array}{l}\text { Durante el tiempo } \\
\text { que duren sus estu- } \\
\text { dios, hasta un máxi- } \\
\text { mo de } 5 \text { años. }\end{array}$ \\
\hline México & $\begin{array}{l}\text { Residente temporal } \\
\text { de estudiante }\end{array}$ & $\begin{array}{l}\text { Visa / Se autoriza la } \\
\text { entrada y salida del } \\
\text { país y la realización } \\
\text { de actividades remu- } \\
\text { neradas. }\end{array}$ & $\begin{array}{l}\text { Por el tiempo que } \\
\text { dure los cursos, estu- } \\
\text { dios o proyectos de } \\
\text { investigación o for- } \\
\text { mación. }\end{array}$ \\
\hline Nicaragua & Residente temporal & $\begin{array}{l}\text { No se necesita visa } \\
\text { de ingreso (Decreto } \\
\text { Presidencial No. 57- } \\
\text { 2005). }\end{array}$ & $\begin{array}{l}\text { Mientras dure su ac- } \\
\text { tividad. }\end{array}$ \\
\hline Panamá & Residente temporal & Visa. & $\begin{array}{l}\text { Mientras dure su ac- } \\
\text { tividad. }\end{array}$ \\
\hline Paraguay & $\begin{array}{l}\text { Residente tempora- } \\
\text { rio }\end{array}$ & & $\begin{array}{l}\text { Mientras dure su ac- } \\
\text { tividad. }\end{array}$ \\
\hline
\end{tabular}




\begin{tabular}{|c|c|c|c|}
\hline PAÍS & CATEGORÍA & $\begin{array}{c}\text { ¿SE DEBE } \\
\text { REALIZAR UN } \\
\text { TRÁMITE } \\
\text { ESPECIAL? }\end{array}$ & $\begin{array}{c}\text { TIEMPO } \\
\text { MÁXIMO DE } \\
\text { PERMANENCIA }\end{array}$ \\
\hline Perú & $\begin{array}{l}\text { Inmigrantes tempo- } \\
\text { rarios / residentes }\end{array}$ & $\begin{array}{l}\text { Fines de estudio en } \\
\text { Instituciones o cen- } \\
\text { tros educativos reco- } \\
\text { nocidos por el Esta- } \\
\text { do. } \\
\text { No pueden percibir } \\
\text { rentas con excepción } \\
\text { de prácticas profesio- } \\
\text { nales o trabajos en } \\
\text { periodos vacaciona- } \\
\text { les. }\end{array}$ & $\begin{array}{l}90 \text { días, con prórroga } \\
\text { hasta un año / Un } \\
\text { año renovable. }\end{array}$ \\
\hline Uruguay & $\begin{array}{l}\text { Residente Tempora- } \\
\text { rio }\end{array}$ & Permiso de turista & $\begin{array}{l}90 \text { días a ser renova- } \\
\text { dos por el mismo } \\
\text { tiempo. }\end{array}$ \\
\hline Venezuela & $\begin{array}{l}\text { Migrantes tempora- } \\
\text { les. }\end{array}$ & & $\begin{array}{l}\text { Mientras dure su ac- } \\
\text { tividad. }\end{array}$ \\
\hline $\begin{array}{l}\text { República } \\
\text { Dominicana }\end{array}$ & No residentes. & $\begin{array}{l}\text { No pueden realizar } \\
\text { actividades lucrativas. }\end{array}$ & 60 días. \\
\hline
\end{tabular}

De acuerdo a esta comparación, se puede establecer que en todas las legislaciones analizadas, los estudiantes adquieren una categoría migratoria específica cuya permanencia en el país extranjero depende del tiempo que duren sus estudios, observándose también en algunos casos, de manera expresa, un tiempo máximo de un año, siendo el más restrictivo Uruguay en donde su duración es de 90 días. Se destaca Bolivia, Chile y Nicaragua cuyas políticas migratorias facilitan incluso la permanencia para el ejercicio profesional, en donde se considera a los estudiantes, e investigadores como un potencial para coadyuvar al desarrollo de estos países.

No debemos olvidar que las leyes y políticas migratorias establecen en la mayoría de estados un trámite de visa, como requisito para el ingreso y permanencia en el país extranjero, en donde se deben cumplir con un sinnúmero de requisitos para obtener la categoría de «residente» y se faculte la realización de las actividades académicas autorizadas. De la totalidad de los países se observa que el $83 \%$ de éstos exigen la presentación de requisitos especiales que deben ser cumplidos por los interesados, siendo casi similares, con ciertas diferencias de acuerdo a las políticas de cada uno de los estados objeto de nuestro estudio, y que dificultan pero no imposibilitan la obtención de visas, en este caso concreto la de Estudiante; mientras que existe un porcentaje de legislaciones-países que en beneficio propio 
quitan estas barreras y facilitan la migración estudiantil hacia sus territorios.

Existe en la región un convenio de creación de la visa única centroamericana para la libre movilidad de extranjeros entre las naciones de El Salvador, Guatemala, Honduras y Nicaragua, desde el año 2005, el cual define según el país de origen del ciudadano que desea visitar cualquiera de estos cuatro países. Así mismo, manifiestan que dependiendo de la nacionalidad que venga el extranjero necesitará un tipo de visa ${ }^{19}$.

\section{DIFERENCIAS DE CALIDAD EN LA EDUCACIÓN SUPERIOR EN AMÉRICA LATINA Y EL CARIBE}

\section{III.1. Diferencias en los sistemas educativos}

Finalmente el tercer problema identificado para la creación de este espacio, son las notables diferencias existentes en los sistemas de educación universitaria en lo que se refiere a la calidad de la educación e investigación y la inversión en ciencia y tecnología.

Ello se refleja además en las diferencias económicas y de extensión geográfica, es así que tenemos naciones sumamente pobladas y otras con población mínima así como su territorio, las que superan los 13 millones de habitantes, son en su orden: Brasil (195), México (107), Colombia (46), Argentina (39), Perú (28), Venezuela (27), Ecuador (13) y Guatemala (13) y los menos poblados pertenecientes al Caribe que no superan los trescientos mil habitantes están desde el más pequeño: Dominica (67 mil), Antigua y Barbuda (86 mil), Granada (106 mil), San Vicente y las Granadinas (121 mil) entre otros. Tenemos países con alto índice de migración lo que se ve reflejado en los flujos de remesas en donde los países pertenecientes al Caribe y Centro América ocupan los primeros lugares: Guyana, Haití, Honduras, El Salvador, Jamaica, Nicaragua, Guatemala, Belice, y en Sur América Bolivia, Ecuador, siendo los que menor índice tienen Venezuela, Argentina, Chile, Uruguay y Brasil.

${ }_{19}$ Agradezco la colaboración en este apartado al Ab. Edison Patricio Rivas Rodríguez, docente de la Escuela de Derecho de la Universidad Técnica Particular de Loja, Ecuador, quien realizó el levantamiento de información sobre las leyes y políticas migratorias en los países de Latinoamérica y el Caribe. 
Nuestra realidad económica evidencia pocos países que se constituyen en la principal economía de la región que lo son Brasil y México y otras con pobreza extrema como Haití. De todas maneras en todos los países se evidencian zonas rurales en donde se vive con menos de 1,25 dólares por persona diarios. "En las Américas una cantidad significativa de población no cuenta con los recursos para satisfacer sus necesidades básicas, aun cuando debe considerarse que al menos en América Latina disminuyó de manera considerable entre 2000 y 2007. Si bien en los últimos años la distribución del ingreso ha mejorado en alguna medida, la inequidad permanece como uno de los rasgos distintivos de los países de las Américas en comparación con otras regiones. ${ }^{20}$

Algunos indicadores sobre ciencia y tecnología en la región nos muestran la diversidad existente:

- El gasto en investigación y desarrollo de países como Ecuador, Perú y Colombia registran los más bajos porcentajes (no llegan al 0,05\% del PIB), mientras que Brasil tiene el mayor porcentaje (un poco más del 1\%) seguido de Chile.

- La producción científica en América Latina es muy por debajo de los países desarrollados, solamente contribuimos al 4\% de del total a nivel mundial en el 2002 a un poco más del 5\% en el 2007.

- Los programas de doctorado se encuentran concentrados en tres naciones, Brasil, México y Argentina, con porcentajes de $48,3 \%, 18,5 \%$ y $13,3 \%$ respectivamente.

- El mayor número de publicaciones científicas lo tienen Brasil, México y Argentina en un número de 9.889, 3.902 y 3.058 en su orden, mientras que solamente Estados Unidos registra 205.320 publicaciones. En general exceptuando los países mencionados y Venezuela y Colombia que registran un poco más de mil, todos los países de Latinoamérica y el Caribe cuentan con menos de 1.000 publicaciones al año ${ }^{21}$.

${ }^{20}$ Quinta cumbre de las Américas 1994-2009, Indicadores seleccionados, Naciones Unidas, abril de 2009, pág. 25.

21 Esta misma tendencia se desarrolla desde la década de los noventas, en donde el desarrollo científico en esta región se produjo por ocho países: Brasil (2.723; 34.0\%), Argentina (1.840; 23.0\%), México $(1.340 ; 16.7 \%)$, Chile $(916 ; 11.4 \%)$, Venezuela (437; $5.5 \%)$, Colombia (145; $1.8 \%)$, Cuba $(142 ; 1.8 \%)$ y Perú $(106 ; 1.3 \%)$. Los restantes 11 países contribuyeron solo con el $4.5 \%$ de las publicaciones totales de la región. VILLEGAS, R., y CARDOZO, G., "La Investigación en Ciencia y tecnología en las Universidades, Centros de Investigación y de Estudios avanzados de América Latina: el papel 
- De acuerdo al informe de educación Superior en Iberoamérica, en nuestra región las publicaciones científicas las realizan alrededor de 20 universidades de Brasil, Argentina, México, Chile, Venezuela y Colombia. (Se incluyeron solamente lo países que constan en el Atlas of Science 2006 y las instituciones que durante el período 1990-2004 producen mil o más artículos científicos registrados en bases de datos Thomson Scientific-ISI y reúnen un $2 \%$ más de la producción nacional total) y de acuerdo al ranking iberoamericano de producción científico técnica, las universidades que se dedican a investigación son muy pocas ya que encontramos solamente 3 en Brasil (Universidad de Sau Paulo, Universidad de Campinas y Universidad Federal de Rio de Janeiro), 1 en México, Argentina y Chile (Universidad Nacional Autónoma de México, Universidad de Buenos Aires y Universidad de Chile, respectivamente), y además en la evolución de la producción científica medida por países, Brasil es en Iberoamérica (luego de España) el que mayor incremento ha tenido en los últimos años, seguido por México y Argentina ${ }^{22}$.

- El número de patentes en nuestra región de igual manera es bajo con relación a los países desarrollados (Estados Unidos registra alrededor de 210.062 solicitudes de patente en un año), mientras que Brasil, México y Argentina son los países con mayor número en nuestra Región, (solamente contribuimos al $3,2 \%$ del total de patentes a nivel mundial ${ }^{23}$ ).

Debemos recordar además que una gran parte de la población en América Latina y el Caribe vive en zonas rurales y sobre todo en países Andinos como Bolivia, Ecuador y Perú existe un alto porcentaje de pueblos indígenas que no tienen acceso a Universidades ni educación superior, ello debido a la baja calidad de la educación básica y media que limita por tanto el acceso a una Universidad.

Por otro lado con la expansión de la educación superior en América Latina y el Caribe, producida en la década de los noventa ${ }^{24}$, que

de la integración regional», en LóPEz OsPINA G., (Comp.) Reunión Internacional de Reflexión sobre los Nuevos Roles de la Educación Superior a Nivel Mundial: el caso de América Latina y del Caribe, futuro y escenarios deseables, Caracas, Unidad de Artes Gráficas y reproducción UNESCO/CRESALC, 1991, p. 66.

${ }^{22}$ Centro Interuniversitario de Desarrollo CINDA, Educación Superior en Iberoamérica, Informe 2007, Santiago de Chile, RIL® Editores, 2007, pág. 83; 166. Ver además pág. 40 Espacios Iberoamericanos, vínculos entre universidades y empresas para el desarrollo tecnológico.

${ }^{23}$ Ibídem, pág. 170.

${ }^{24}$ La expansión matricular se ha producido desde fines de los ochenta, y se ha 
se evidencia con la creación de nuevas leyes de educación superior y/o reformas en estas leyes, así como en las constituciones de la mayoría de países, también se acentuaron las diferencias en la educación superior, su sistema e instituciones, tanto al interior de cada estado como entre una y otra nación. Ya no solamente la diferencia está dada en universidades públicas y privadas o en sistemas de educación que incluyen instituciones universitarias y no universitarias, sino diversidad en tamaño: macro universidades (con más de 100.000 estudiantes) o micro universidades (con menos de 2.000 estudiantes); con varias modalidades de estudio: presencial, semi presencial, a distancia; nos encontramos con instituciones con diferencias en reputación y prestigio, que hacen investigación, y otras que se centran netamente en funciones de docencia; de gran calidad y exigencia con otras de dudosa reputación científica; el uso de diferentes medios para producir y trasmitir conocimiento, como la utilización de nuevas tecnologías y otras en donde no es posible encontrar condiciones adecuadas para el desarrollo de actividades académicas y peor aún de investigación; programas de estudio cada vez más variados y nuevos. Diferencias en cuanto al financiamiento de las IES, algunas que reciben un alto porcentaje por parte de los gobiernos y otras que deben buscar recursos sobre todo para investigación en otras fuentes.

En Iberoamérica (se incluye Portugal y España), el crecimiento de la matrícula durante las últimas décadas ha sido muy amplio, pasando de cerca de 4 millones en 1975 a 8,5 millones en 1995 hasta llegar a cerca de 16 millones en el 2004, además continúan expandiéndose a tasas que fluctúan entre un 3\% y $7 \%$ a excepción de Brasil que crece a cerca del 12\%, mientras que en Portugal se encuentra estancada y en España va disminuyendo lentamente ${ }^{25}$.

En cuanto a las tasas brutas de matrícula y concentración de la misma, tenemos varias fuentes: en la primera se presentan valores que van del 87,9\% en Cuba y el 8,7\% en Guatemala, Argentina el $50 \%$, Chile, Uruguay, Panamá, Bolivia y Venezuela registran porcentajes entre el 40 y 45\%. Perú, República Dominicana, Colombia, México, Brasil, Paraguay y Costa Rica están entre el 25 y $35 \%$ y final-

acelerado a mediados de los 90. Mientras en 1994 había en promedio en la región 162 estudiantes terciarios por cada 10 mil habitantes, para el año 2003 alcanzaron a 259 por cada 10 mil habitantes. METAS EDUCATIVAS 2021 La educación que queremos para la generación de los Bicentenarios, Organización de Estados Iberoamericanos para la Educación, la Ciencia y la Cultura, Madrid septiembre de 2008, pág. 36.

${ }_{25}$ Centro Interuniversitario de Desarrollo CINDA, op. cit. p. 105. 
mente los países centroamericanos como El Salvador, Nicaragua y Honduras registran tasas inferiores al 20\% ${ }^{26}$.

En otra fuente, al 2003 la distribución de la matrícula en nuestra región estaba concentrada en tres países: Brasil (28\%), México (17\%) y Argentina $(14 \%)^{27}$, además se observa que cada vez más la concentración de la matrícula se encuentra en las universidades privadas (en Chile y Brasil supera el 75\% del total de la matrícula) ${ }^{28}$. La matrícula del sector privado se ha elevado en alrededor del $30 \%$ y la del sector público en 5\% para el año 2005 y la matrícula de estas se concentran en carreras de cuatro años de contenido académico profesional.

\section{III.2. Diferencias en la calidad de la enseñanza en los diferentes países de la Región}

Finalmente es necesario abarcar como parte de este tercer problema identificado para la creación de un espacio común de educación superior, el tema de la calidad en la Región, ya que para hablar de unificación de los currículos académicos, es necesario contar con criterios de calidad y evaluación también comunes en nuestros países. La necesidad de mejorar la calidad de la educación superior y de sus instituciones, se instaló con mayor fuerza como parte de las políticas educativas de la década de los noventas ${ }^{29}$, que para muchos obedeció también a la proliferación de instituciones privadas. El contexto de nuestros países es la existencia de diferentes criterios de evaluación de acreditación, tanto de instituciones como de carreras, que van desde la obligatoriedad de hacerlo para todas las IES, en otras solamente para las Universidades públicas, o solamente universidades privadas, universidades públicas y privadas, etc. procesos que incluyen la autoevaluación, evaluación por pares y finalmente la

26 Metas educativas 2021, p. 36.

27 Fuente: Sobre la base de The Task Force on Higher Education and Society, The World Bank 2000, Statistical Appendix Informes Nacionales, 2006; IESALC, Informe sobre la Educación Superior en América Latina y El Caribe 2000-2005, 2006; UNESCO, Global Education Digest 2006.

28 Centro Interuniversitario de Desarrollo CINDA, op. cit. p. 112.

29 Para RAma Claudio, la calidad de la educación superior inició de manera «intrínseca» desde la I Reforma de la Educación Superior en América Latina generada a partir del movimiento de Córdoba en 1918. RAMA C., «Los sistemas de control de la calidad de la educación superior en América Latina en la III reforma Universitaria», en IESALC-UNESCO, La evaluación y la acreditación de la educación superior en América Latina y el Caribe, Venezuela, (s/a), p. 277. 
acreditación. Estos procesos involucran la participación y recursos tanto del gobierno como de las autoridades de las IES, ya que deben poner a prueba y transparentar sus procesos, la calidad académica y muchas veces de investigación que ofrecen a la sociedad.

Si consideramos a la educación como un bien público y derecho de todos y todas, debe así mismo ser un deber del Estado proporcionar o por lo menos sentar las bases para que esta educación sea de "calidad», asociada a su vez a criterios de equidad, inclusión y responsabilidad social, atendiendo además a la diversidad cultural que encontramos en nuestras naciones. El reto está en emitir criterios y políticas comunes en nuestros países cuya realidad es la disparidad en el acceso a la educación, tipos de IES y sistema de educación superior, asociado en gran medida a la inversión en ciencia y tecnología y por ende en publicaciones científicas, patentes, etc.

Al considerar algunos conceptos sobre calidad, debemos centrarnos en cuál sería el más pertinente para nuestra región y para la educación superior ${ }^{30}$ :

a) Calidad como excepción con sus tres variantes: vista como algo de clase superior, de carácter elitista y exclusivo; la equivalente a excelencia y la entendida como el cumplimiento de estándares mínimos.

b) La calidad como perfección o consistencia: con dos premisas «cero defectos» y la de "hacer las cosas bien».

c) La calidad como aptitud para el logro de una misión o propósito: en donde se ajusta a lo determinado por el «cliente»o «usuario».

d) La calidad como valor agregado: responsabilidad frente a los organismos financiadores.

e) La calidad como transformación: satisfacción de necesidades, cambios y enriquecimiento de los alumnos.

En si el concepto de calidad se utiliza como un término de referencia para realizar una comparación con algo «mejor» o "peor», y que además podamos medir con algo homologable entre sí, la interrogante sería entonces ¿con quién deberíamos compararnos?, ¿Qué

30 Para ello tomamos los conceptos de calidad de Harvey y Green 1993 señalado en Dias SobrinHo, J., «Calidad, pertinencia y responsabilidad social de la Universidad Latinoamericana y Caribeña», en Gazzola A. L., DidRIKsson A., (Eds.), Tendencias de la Educación Superior en América Latina y el Caribe, Caracas, IESALC-UNESCO, 2008, p. 90. 
estándares o parámetros mínimos deberíamos establecer para «medir» ${ }^{31}$ y lograr una educación de calidad?, ¿Qué buscamos alcanzar como región?, ¿En qué debemos mejorar o invertir nuestros recursos?. Es claro que la necesidad de la internacionalización de la educación superior nos lleva a tratar de alcanzar parámetros mínimos comparados con instituciones que han alcanzado un prestigio y han desarrollado «ciencia» pero sin embargo debemos estar conscientes que nuestras realidades son distintas y diversas.

Para Dias Sobrinho, «están en pugna dos tipos de paradigmas de calidad. Unos la conciben según criterios que pretenden ser objetivos y universales, valorando más el rigor científico y los aspectos cuantitativos y medibles, identificados con términos y esquemas económicos, como índices de desarrollo, rentabilidad, cálculos de costo-beneficio, eficiencia, rendimientos económicos de las inversiones, tasas de crecimiento cuantitativo con relación a matrículas, tiempos de formación, proporción profesores-estudiantes, indicadores de la producción científica, expansión de los sistemas, medición de desempeño, rendimientos de estudiantes, capacidad de captación de recursos en variadas fuentes, empleabilidad, etc. Otros, sin negar muchos de estos importantes aspectos, consideran también relevantes las realidades políticas y sociales de las instituciones y los sistemas educativos, las dimensiones cualitativas, como actitudes éticas y valores cívicos, insertando la educación superior en las estrategias nacionales o regionales de consolidación de la democracia, desarrollo sostenible de la ciudadanía y de la economía nacional, respetando las identidades culturales y los ideales de la cohesión de los pueblos»32.

Pasaríamos entonces a otro concepto que es el de pertinencia, que está vinculada a la relación de universidad -investigación- sociedad, y es que las IES deben acoplarse a las necesidades de la sociedad, en su entorno local, nacional, regional y mundial; somos los llamados a buscar soluciones a los problemas que nos rodean: pobreza, alimentación, medio ambiente, educación, salud, tecnología, industria, respetando la diversidad cultural y los derechos humanos, buscando por ende que esta educación de calidad sea incluyente oportuna y de responsabilidad social, entonces los parámetros de medición para la evaluación de la calidad de las IES deben adecuarse también a la misión de las instituciones (búsqueda de la verdad, ética, libertad de pensamiento, etc.) y función dentro de la sociedad y

${ }^{31}$ Hay que considerar que «la educación es un fenómeno social, y no todos sus atributos y dimensiones son medibles», ibídem, pág. 91 .

32 Ibídem pág. 92. 
servicio a la comunidad, ello sin embargo no inhibe que, con el esfuerzo, dedicación y preparación adecuada podamos buscar niveles y parámetros que estén a la par de los países e instituciones desarrollados $^{33}$.

Recordemos además que en la conferencia mundial sobre Educación Superior en América Latina y el Caribe CMES (1998), tuvo como objetivo central el ofrecer un marco teórico consensuado para transformar la Educación Superior en América Latina, sobre todo para conducir los procesos de transformación de las Instituciones de Educación Superior (IES), de carácter público e incluso privado, mediante la evaluación institucional, perfeccionando los sistemas de gestión y financiamiento, considerando a la Universidad como un agente clave de transformación de la sociedad. Y en este mismo aspecto, IESALC-UNESCO tiene entre sus objetivos, la acreditación y calidad de la educación superior con la promoción de mecanismos nacionales y regionales de fortalecimiento de la calidad de la educación superior además de actuar como centro de apoyo en la Región para los procedimientos de acreditación y evaluación.

La evaluación generalmente conduce a un proceso de acreditación, que de acuerdo a la normativa de nuestros países se la realiza para las instituciones, carreras o programas, en donde se involucra además a actores diversos: alumnos, egresados, profesores, directivos, personal administrativo, sociedad en general (actores claves locales, como municipios, organizaciones gubernamentales, no gubernamentales, etc., es decir emiten su criterio de la función social de la institución) y que por tanto cualquiera que sea su condición: obligatoria o voluntaria para las IES, otorga una garantía y reconocimiento público de la calidad de una institución y/o sistema de educación ya que para ello de cumplir ciertos estándares y parámetros mínimos que inclusive son medidos también con su capacidad instalada: laboratorios, bibliotecas, aulas, etc. Podríamos pensar que para que una institución sea reconocida y genere un impacto en su localidad, su país, su región o en el mundo, no necesariamente debe incluir un proceso de evaluación y acreditación, ya que ello podría ser medido

33 Debemos cuidarnos de no aceptar la educación como bien público «global», sin consideración de las realidades locales y compromisos nacionales, en especial de las sociedades de los países no-industrializados ya que ello tendría como consecuencia la apertura para la invasión física y virtual de las instituciones trasnacionales a las que las cataloga como casi siempre de calidad dudosa. Además de considerar que no todos los criterios internacionales y trasnacionales de calidad, ni tampoco todas las estrategias de los sistemas educativos de los países ricos son necesariamente adecuados o importantes para las naciones pobres y en desarrollo. DiAS SOBRINHO. 
por su propiedad intelectual: publicaciones, invenciones, descubrimientos, investigaciones, y posiblemente por su servicio a la comunidad y su función social. Sin embargo la realidad que habíamos analizado anteriormente nos conduce a determinar que la calidad de las IES en Latinoamérica y el Caribe es todavía muy desigual y por tanto hace falta a través de políticas de gobierno que se generen estándares mínimos y que la comunidad en general se sienta respaldada en que la educación como derecho de todos y todas y como deber del estado cumpla criterios al menos mínimos y estándares de calidad que garantice además que los estudiantes adquieran las mismas competencias sea en uno u otro país y/o universidad, criterio necesario para la creación de un espacio común de educación superior y la movilidad académica.

\section{CONCLUSIONES}

De los problemas legales identificados: supremacía de la normativa interna por sobre la internacional y el proceso para su incorporación en cada país y la no libertad de movilidad asociada a las políticas y leyes migratorias existentes en nuestros países, podemos concluir lo que sigue:

a) Pese a no existir una Organización Regional de vinculación legal obligatoria en la normativa interna de los países de Latinoamérica y el Caribe, en teoría, luego de analizar las diferentes constituciones y basados en el derecho internacional, nuestra normativa obedece a una escuela monista en donde el derecho interno y el derecho internacional son capaces de unirse, con cuatro maneras de incorporar y jerarquizar los instrumentos internacionales: supraconstitucional, constitucional, supralegal y legal.

Encontramos aspectos comunes como: en la mayoría de países se promueve la integración regional y Latinoamericana y del Caribe y en algunos casos la creación de un organismo internacional supranacional; encontramos la presencia de algunos principios como la prevalencia de los derechos humanos, la igualdad entre los estados, la solidaridad y cooperación, entre otros.

Al reconocer los derechos humanos (derecho a la educación), y los tratados internacionales dentro de las constituciones de nuestras naciones, se puede aplicar para la incorporación 
de un espacio común de educación superior el principio pro homine y si surgiere un conflicto entre el derecho interno y el internacional se estará a lo establecido en la Convención de Viena.

b) En el segundo problema legal identificado, se observa que en la mayoría de países dentro de las categorías migratorias existentes, encontramos una específica que enmarca a los estudiantes y profesores y que permite realizar actividades netamente académicas y cuya permanencia en el país extranjero depende del tiempo que duren sus estudios que van desde un máximo de un año a 90 días en Uruguay.

De la totalidad de los países se observa que el $83 \%$ de éstos exigen la presentación de requisitos especiales para la obtención de visas, siendo casi similares, con ciertas diferencias de acuerdo a las políticas de cada uno de los estados mientras que existe un porcentaje de legislaciones -países que en beneficio propio quitan estas barreras y facilitan la migración estudiantil hacia sus territorios.

c) Finalmente en el tercer problema identificado referente a la heterogeneidad de los sistemas de educación superior, acceso a la educación y calidad en nuestra región nos encontramos con realidades muy disímiles que van desde lo económico y social, como: pocos países que se constituyen en la principal economía de la región que lo son Brasil y México y otras con pobreza extrema como Haití; a su vez Brasil, México, Chile, Argentina, son los países con mayor inversión en ciencia y tecnología, se concentran los programas de doctorado y publicaciones científicas, en este se incluyen países como Venezuela y Colombia.

En cuanto a la calidad de la educación superior y sus instituciones nos encontramos con contextos también muy diversos, desde macro universidades con más de 100.000 estudiantes a micro universidades con menos de 2.000, universidades de mucho prestigio y otras de dudosa creación, unas dedicadas a la docencia e investigación y otras centradas en la enseñanza. Pese a ello y a que los sistemas de acreditación de la calidad difieren entre nuestros países, encontramos que la necesidad de mejorar la calidad de la educación superior y de sus instituciones, surge desde la década de los noventas y se ha ido consolidando dentro de las políticas de educación superior convirtiéndose en una necesidad para las IES. 
Si el contexto en general de nuestros países es considerar a la educación como un bien público y derecho de todos y todas, debe constituirse como un deber del Estado y proporcionar o por lo menos sentar las bases para que esta educación sea de «calidad», asociada a su vez a criterios de equidad, inclusión y responsabilidad social, atendiendo además a la diversidad cultural que encontramos en nuestras naciones.

Hoy en día, eliminadas las barreras de las comunicaciones internacionales, es hora de suprimir las fronteras intelectuales, educativas, sociales y políticas. Entre los caminos más importantes para lograrlo se encuentra la integración y la cooperación internacional en el ámbito de la educación y de la investigación, lo que contribuirá a que el derecho a la educación proclamado en nuestras constituciones pueda ser una realidad y ayude a mejorar la situación económica y social, aminorando las brechas y las inquietantes diferencias existentes en los países de Latinoamérica y el Caribe. 
